\title{
IT Aptitude Testing Program Development Course for SW Education
}

\author{
Kyeong Hur ${ }^{1}$, Won-Sung Sohn ${ }^{1 *}$ and Kil Young Kwon ${ }^{2 \dagger}$ \\ ${ }^{1}$ Dept. of Computer Education, Gyeongin National University of Education, \\ Gyesan-Dong San 59-12, Gyodae-Gil 45, Gyeyang-Gu, Incheon, 407-753, Korea \\ ${ }^{2}$ Dept. of Family Medicine, Eulji General Hospital, Hagye-Dong 280-1, \\ Hanguelbiseok-street 68, Nowon-Gu, Seoul, 139-872, Korea \\ Telephone: $+82-32-540-1284$, \\ Fax:+82-32-548-0288, *sohnws@ginue.ac.kr
}

\begin{abstract}
In the age of the Fourth Industrial Revolution, software education is indispensable. However, there is a lack of effective software development examples in software training for untrained students. Examples of effective software development should include the use of 'divide and conquer' programming techniques and data structures for data storage. In this paper, we defined problem-solving steps using the software. To understand and practice each problem-solving step, we proposed the process of developing IT aptitude test program. The proposed IT aptitude test program was systematically developed in accordance with predefined problem-solving steps. By using the developed IT aptitude testing program, it is possible to educate the problem-solving steps using software and to enhance the understanding of students about the software structure. We also used Scratch 2.0 software provided by MIT University to teach introductory programming subjects for non-specialists.
\end{abstract}

Keywords: Aptitude, Career, Education, Information, Software

\section{Introduction}

In this paper, we defined problem-solving steps using software [1-3]. For the first step, students understand and analyze given problem situations. The second step is researching problem-solving methods. The third step is designing algorithms for your computer to run. In the fourth step, students create a program to save data and use it for operations. Students check results and correcting errors in their programs as the final step.

To understand and practice each problem-solving step, we proposed the process of developing IT aptitude test program. In this example, the given problem theme is 'Let's create a program that examines IT career aptitude!'. For the first step, we can search career internet sites such as career net (www.career.go.kr) [4] and worknet (www.work.go.kr) [5]. Furthermore, we can search for items that examine career aptitude in IT field and list up those items as in Table 1 and Table 2.

The proposed IT aptitude test program was systematically developed in accordance with predefined problem-solving steps. From the second to the fifth steps using software are explained in the following Sections. After five problem-solving steps, students understand 'divide and conquer' programming technique. Furthermore, they study about

Received (January 4, 2018), Review Result (March 8, 2018), Accepted (March 12, 2018)

* Corresponding Author

${ }^{\dagger}$ Co-first Author 
whether their programs can be created by other data storage structures and computation methods.

Table 1. Question Items and Answers

\begin{tabular}{|l|c|c|}
\hline \multicolumn{1}{|c|}{ Question Items } & \multicolumn{2}{|c|}{ Answers } \\
\hline I like conversation with people. & Yes & No \\
\hline I am introspective but I tend to say something. & Yes & No \\
\hline I can never waste my time for others. & Yes & No \\
\hline If there is a problem, it is solved by myself. & Yes & No \\
\hline Present is more important than the future. & Yes & No \\
\hline If there are the latest electronics, you tend to buy it. & Yes & No \\
\hline I plan to do my best and go to work. & Yes & No \\
\hline If a problem arises, it should be resolved immediately. & Yes & No \\
\hline I like the job of a civil servant more than a freelancer. & Yes & No \\
\hline
\end{tabular}

Table 2. IT Job Types

\begin{tabular}{|c|c|}
\hline IT Job Type & IT Job Aptitude Explanation (Judgment) \\
\hline $\begin{array}{l}\text { A type DB } \\
\text { manager }\end{array}$ & $\begin{array}{l}\text { It is a group that mainly conducts the work related to the } \\
\text { installation, maintenance and tuning of database systems in } \\
\text { enterprises, and education and monitoring related to this. It is } \\
\text { calm and meticulous, but there are lots of charismatic stylish } \\
\text { people who can show leadership. }\end{array}$ \\
\hline $\begin{array}{l}\text { B type } \\
\text { Security } \\
\text { expert }\end{array}$ & $\begin{array}{l}\text { Dealing with hacking accidents or information security issues } \\
\text { related to IT, doing consulting, doing business, government agency } \\
\text { or freelance work. They like to explore if there are any progressive } \\
\text { problems, and they have a lot of multi-player occupations with a } \\
\text { wide range of knowledge in the } \Pi \text { field because they are } \\
\text { accomplished, endeavored, innovative and analytical. }\end{array}$ \\
\hline $\begin{array}{l}\text { C type } \\
\text { programmer }\end{array}$ & $\begin{array}{l}\text { There are many different kinds of games, network, web, and } \\
\text { mobile programmer. Usually we design the structure of a program } \\
\text { and integrate various data to complete the program. Patient and } \\
\text { meticulous people do this job with abilities of numeracy, } \\
\text { computation, logical and technical analyses. The working } \\
\text { environment also has to sit in one place and work a long time, so } \\
\text { it may not be suitable for people who are too active. }\end{array}$ \\
\hline $\begin{array}{l}\text { D type } \\
\text { Network } \\
\text { expert }\end{array}$ & $\begin{array}{l}\text { It is an occupation that many companies need in the analysis, } \\
\text { design and construction of the network system. Because of the } \\
\text { nature of work, there is no night work, but there are some } \\
\text { business trips, so it can be a good fit for those who are active. }\end{array}$ \\
\hline
\end{tabular}

\section{2. $2^{\text {nd }}$ and $3^{\text {rd }}$ steps for IT Aptitude Testing Program Development}

The second step is researching problem-solving methods. Based on the input data, the flow of the detailed IT career is judged and the flowchart with all question states is made as in Table 3.

The third step is designing algorithms for your computer to run. Algorithm denotes a detailed description of the procedure or method for resolving a problem based on a reference value so that the computer can follow it [6-8]. So, in this SW development, a 
reference value of 'state value' is assigned to each question state and each aptitude judgment state to four IT career types as in Table 4.

\section{Table 3. Flow of Detailed IT Career}

\begin{tabular}{|c|c|c|}
\hline Question state & \multicolumn{2}{|c|}{ Flow of detailed IT career } \\
\hline Q1 : I like conversation with people. & Yes: go to Q6 state & No: go to Q4 state \\
\hline $\begin{array}{l}\text { Q2: I am introspective but } 1 \text { tend to say } \\
\text { something. }\end{array}$ & Yes : go to Q3 state & No: go to Q7 state \\
\hline Q3 : I can never waste my time for others. & Yes: go to Q6 state & No: go to $Q 9$ state \\
\hline $\begin{array}{l}\text { Q4: If there is a problem, it is solved by } \\
\text { myself. }\end{array}$ & Yes : go to Q9 state & No: go to Q3 state \\
\hline $\begin{array}{l}\text { Q5: Present is more important than the } \\
\text { future. }\end{array}$ & Yes : go to Q4 state & No: go to Q8 state \\
\hline $\begin{array}{l}\text { Q6 : If there are the latest electronics, you } \\
\text { tend to buy it. }\end{array}$ & Yes : go to Q8 state & No: go to Q5 state \\
\hline Q7 : I plan to do my best and go to work. & $\begin{array}{l}\text { Yes : go to A type } \\
\text { Judgment }\end{array}$ & No: go to Q4 state \\
\hline $\begin{array}{l}\text { Q8: If a problem arises, it should be } \\
\text { resolved immediately. }\end{array}$ & $\begin{array}{l}\text { Yes : go to B type } \\
\text { Judgment }\end{array}$ & No: go to Q2 state \\
\hline $\begin{array}{l}\text { Q : I like the job of a civil servant more } \\
\text { than a freelancer. }\end{array}$ & $\begin{array}{l}\text { Yes : go to C type } \\
\text { Judgment }\end{array}$ & $\begin{array}{l}\text { No : go to D type } \\
\text { Judgment }\end{array}$ \\
\hline
\end{tabular}

Table 4. State Value Flow of Detailed IT Career

\begin{tabular}{|c|c|c|}
\hline Question state & \multicolumn{2}{|c|}{ Flow of detailed IT career } \\
\hline Q1: state value $=1$ & Yes: go to Q6 state & No: go to Q4 state \\
\hline Q2: state value $=2$ & Yes : go to Q3 state & No: go to Q7 state \\
\hline $\mathrm{Q}^{3}$ : state value $=3$ & Yes: go to Q6 state & No : go to Q9 state \\
\hline $\mathrm{Q} 4$ : state value $=4$ & Yes : go to Q9 state & No: go to Q3 state \\
\hline Q5 : state value $=5$ & Yes: go to Q4 state & No: go to Q8 state \\
\hline Q6 : state value $=6$ & Yes: go to Q8 state & No: go to Q5 state \\
\hline $\mathrm{Q} 7$ : state value $=7$ & $\begin{array}{l}\text { Yes : go to A type } \\
\text { Judgment }\end{array}$ & No: go to Q4 state \\
\hline Q8 : state value $=8$ & $\begin{array}{l}\text { Yes : go to B type } \\
\text { Judgment }\end{array}$ & No: go to Q2 state \\
\hline $\mathrm{Q} 9$ : state value $=9$ & $\begin{array}{l}\text { Yes : go to C type } \\
\text { Judgment }\end{array}$ & No: go to D type Judgment \\
\hline A type Judgment : state value $=10$ & & \\
\hline B type Judgment: state value $=11$ & & \\
\hline$C$ type Judgment : state value $=12$ & & \\
\hline D type Judgment : state value $=13$ & & \\
\hline
\end{tabular}

\section{3. $4^{\text {th }}$ and $5^{\text {th }}$ steps for IT Aptitude Testing Program Development}

In the fourth step, students create a program to save data and use it for operations. Students select Scratch educational programming language (scratch.mit.edu). Educational programming languages (EPLs) are easier to understand, less time-consuming, and provide step-by-step, immediate feedback compared to traditional programming languages, enabling effective programming education for non-specialists.

In the IT Aptitude Testing program, memory spaces to store nine questions are named as Q1 Q9 variables. Memory space to store the 'state value' is named as state value variable. Complex, large programs divide into smaller functions called as subprograms to solve small problems. And a large program collects small functions to solve big problems. 
In this program, there is one main program and are six subprograms. The main program and six subprograms are explained in the following subsections.

\section{A. Main Program}

Each subprogram is called to perform its function. The structure of the main program is shown in Figure 1.

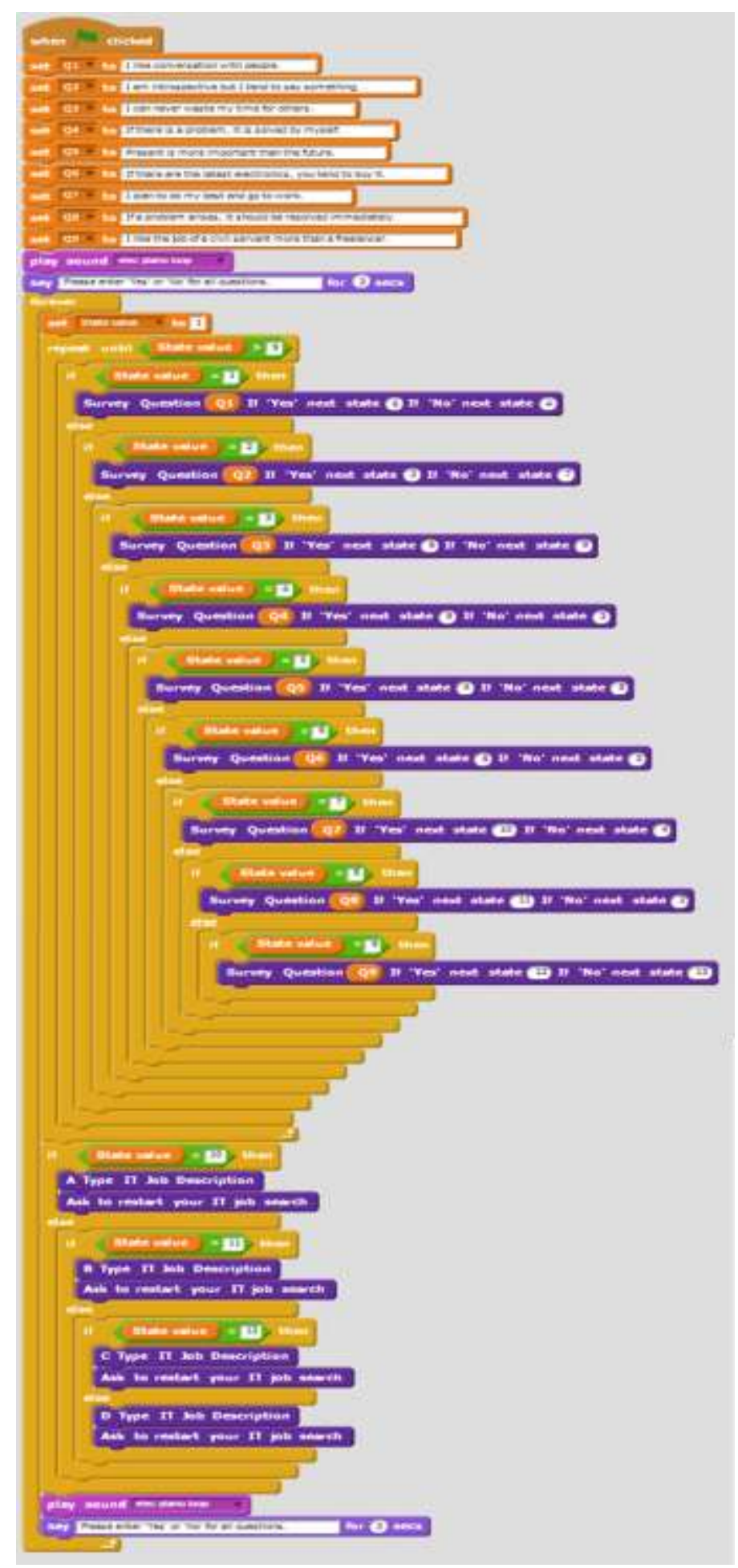

Figure 1. Structure of the Main Program 


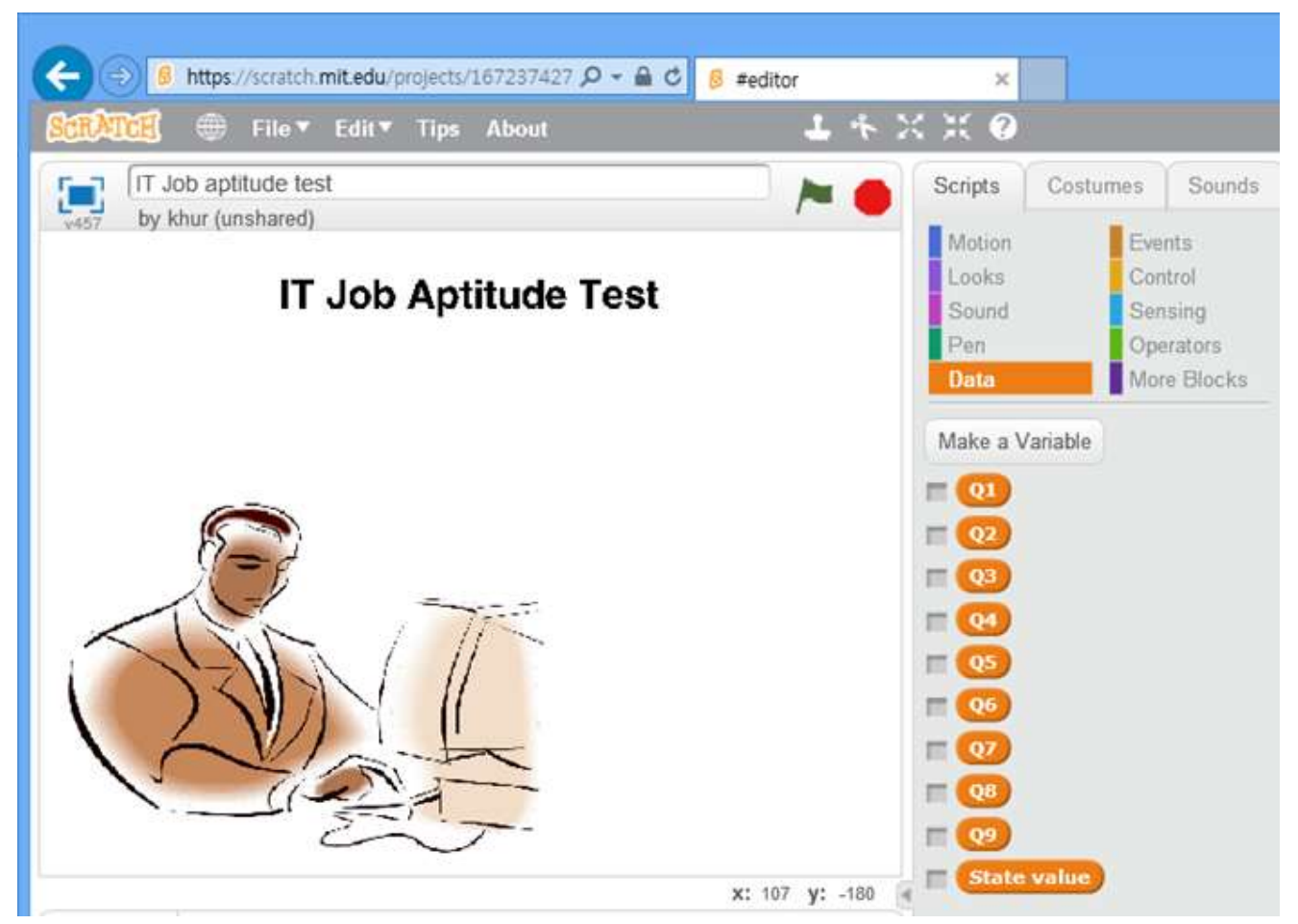

Figure 2. Variables in the Program

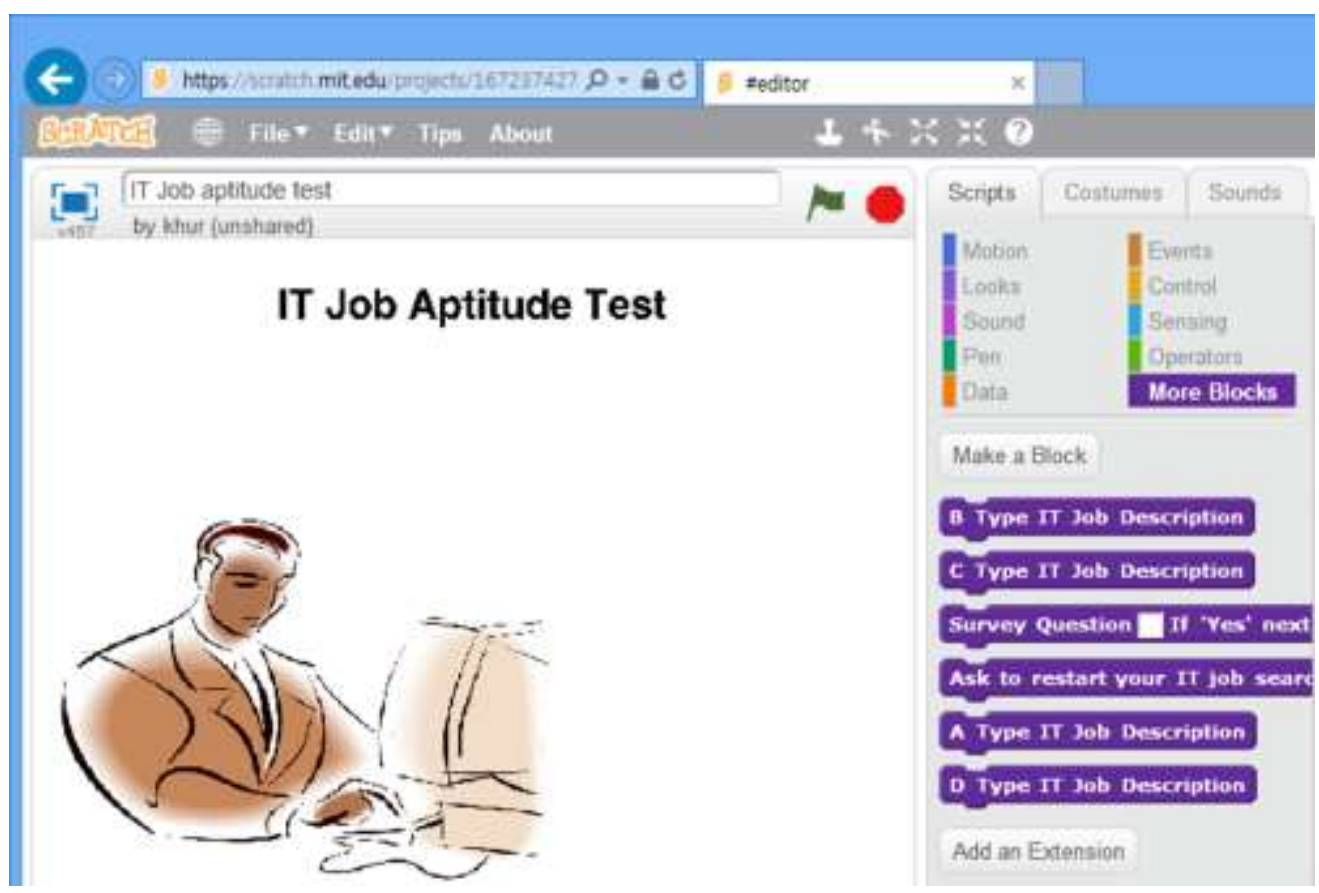

Figure 3. Subprograms in the Program

\section{B. Subprogram - Survey}

The structure of 'Survey' subprogram is shown in Figure 4. It takes one of the nine saved questions from 'string1' and runs it in place. When the answer is 'yes' or 'no', the specified progress status value set to number1 or number2 is input and executed at the corresponding place. This subprogram takes into account the case where an incorrect input is received instead of "Yes" or "No". 


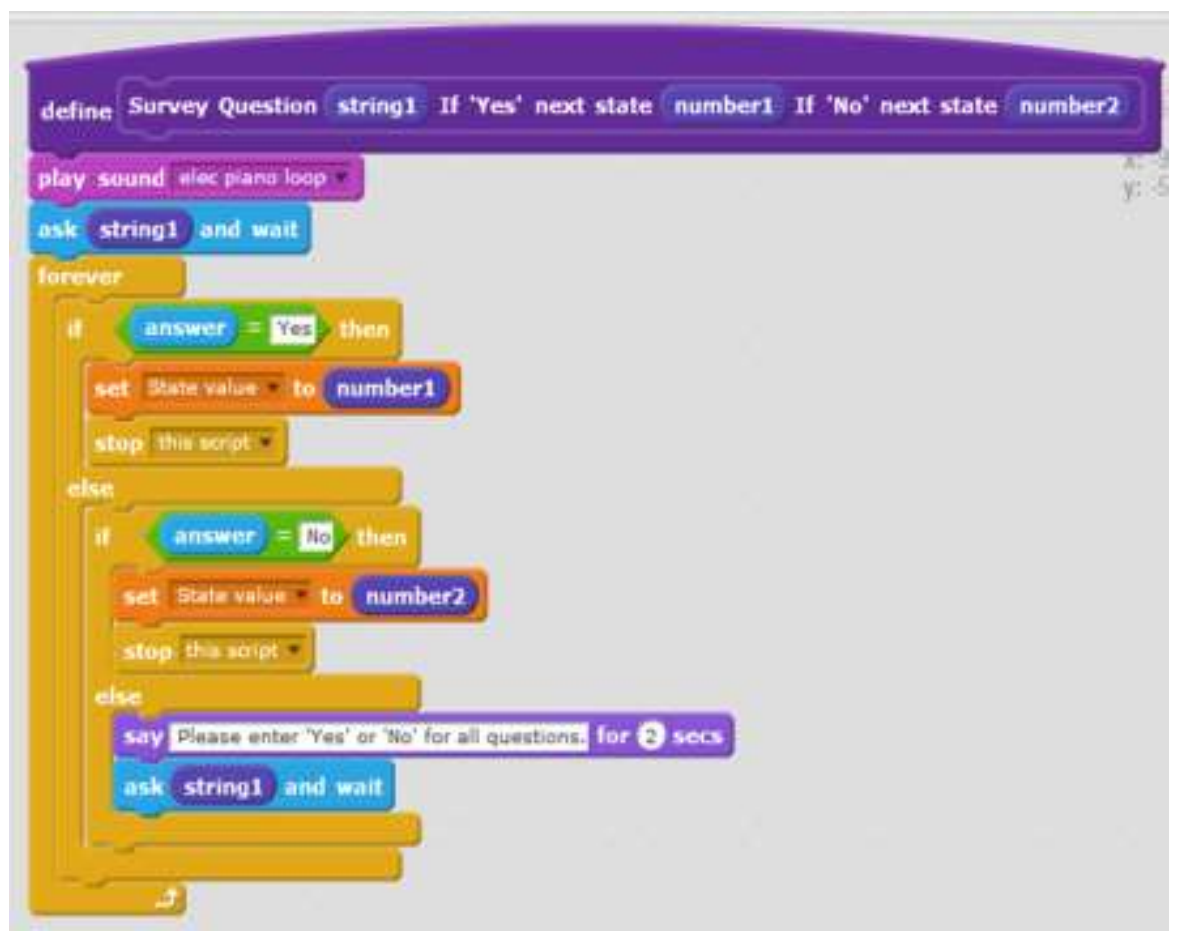

Figure 4. Structure of 'Survey' Subprogram

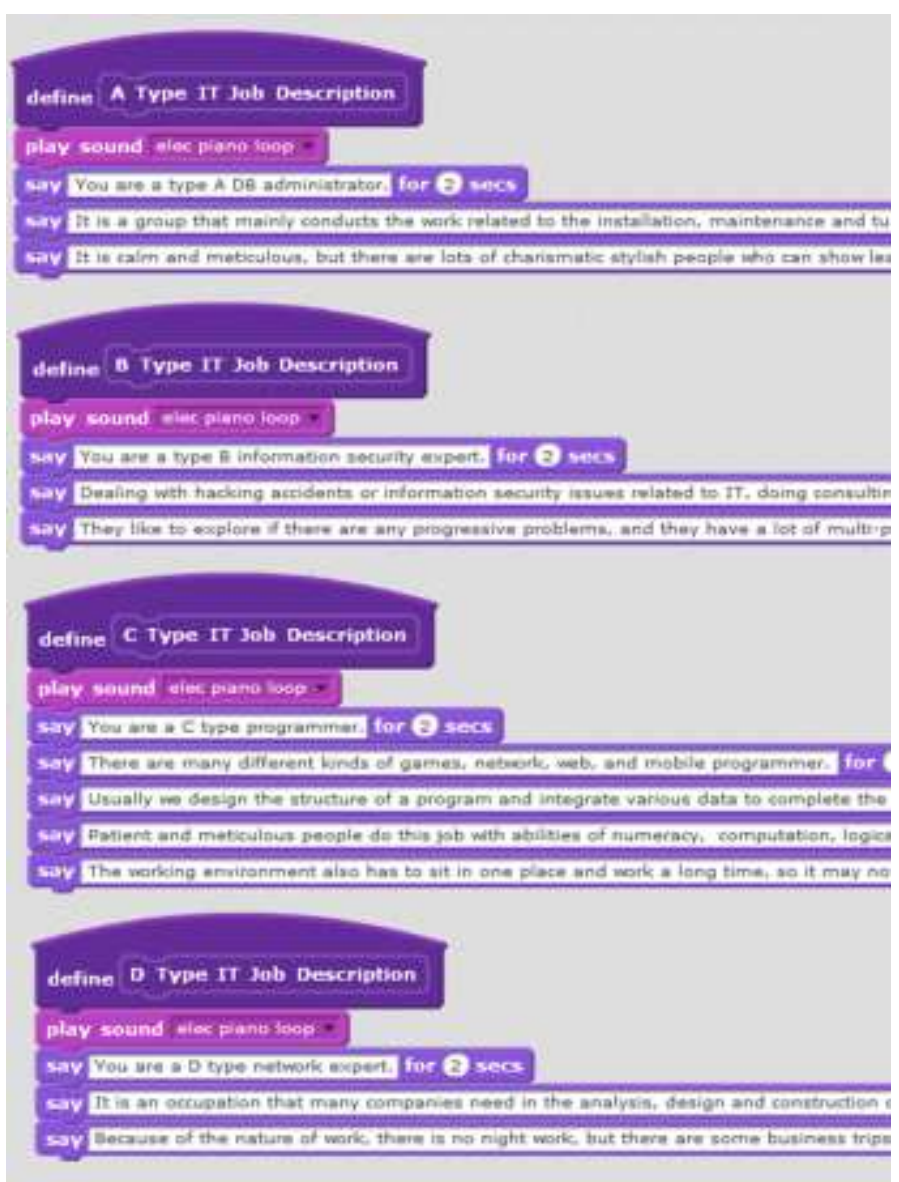

Figure 5. Structure of 'A D Type IT Job Description' Subprograms 


\section{Subprogram - A D Type IT Job Description}

The structure of 'A D Type IT Job Description' subprograms are shown in Figure 5. There are four functions of 'A, B, C, and D Type IT Job Descriptions'. When the corresponding type IT job description block is executed, it is output and shown to the screen.

\section{Subprogram - Ask to Restart your IT Job Search}

The structure of 'Ask to restart your IT job search' subprogram is shown in Figure 6. In this subprogram, 'Stop this script' command can only be escaped from an infinite loop block that is currently running. On the other hand, 'Stop all script' command stops the entire program. This subprogram takes into account the case where an incorrect input is received instead of "Yes" or "No".

Students check results and correcting errors in their programs as the final step. They see the finished scratch program and understand the structure of the program. And they run and review the program for any errors. Finally, students consider whether the program described in this course can be created by other data storage structures and computation methods. The structure of the whole program is shown in Figure 7. 'Divide and conquer' programming technique is explained visually from Figure 7 [9-12].

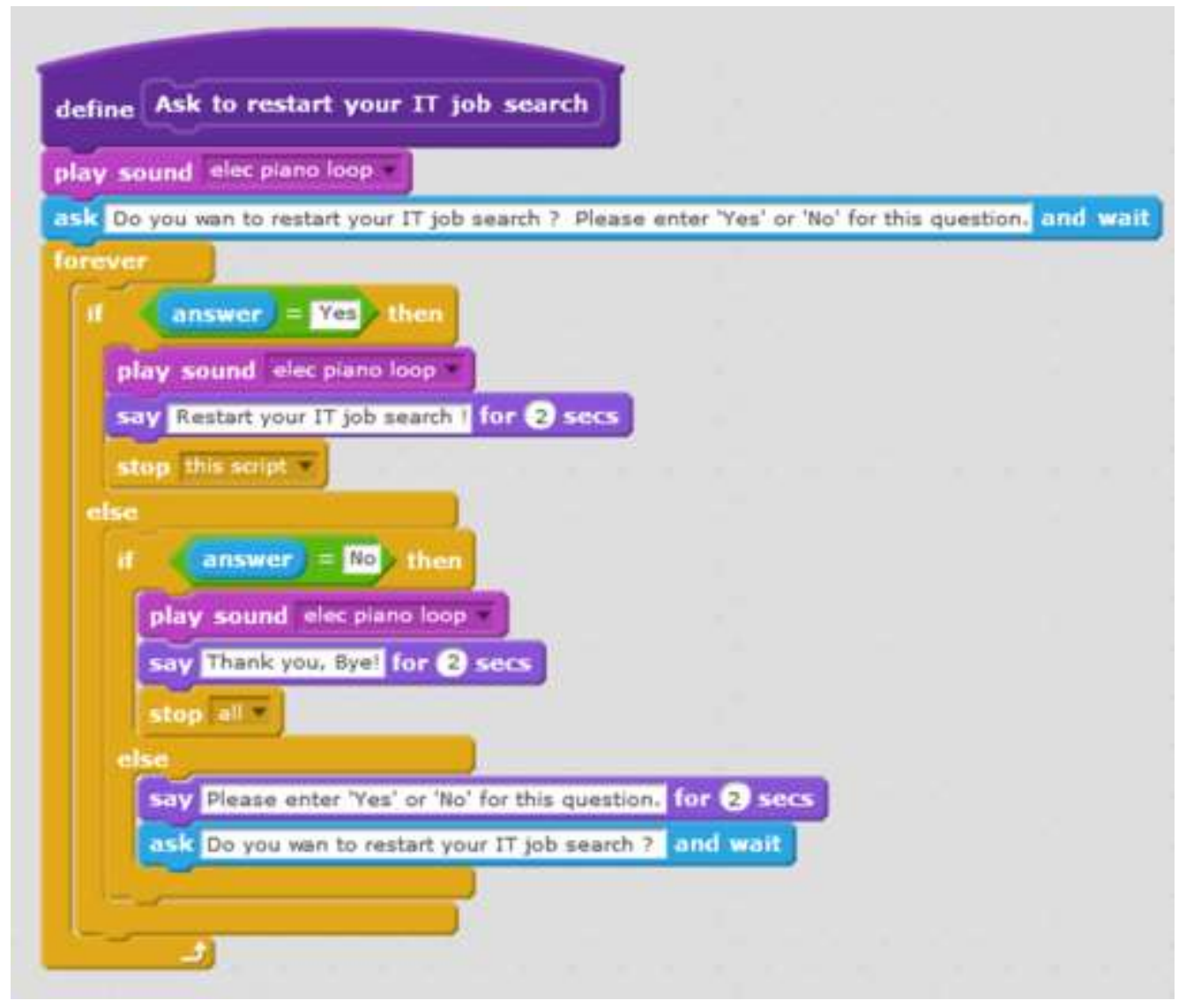

Figure 6. Structure of 'Ask to restart your IT job search' Subprogram 


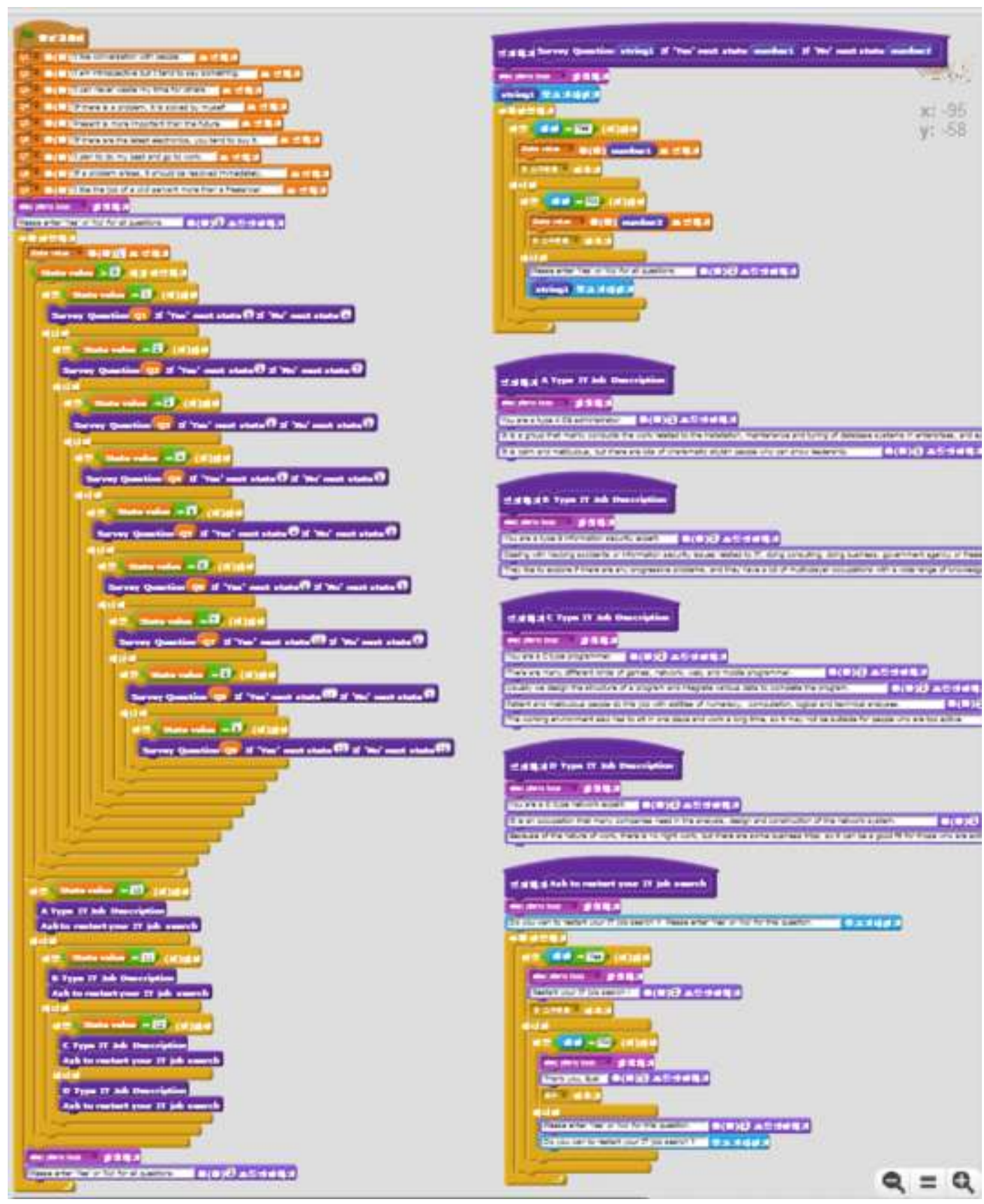

Figure 7. 'Divide and conquer' Programming Technique in the Structure of the Whole Program

\section{E. Development of Aptitude Test Software by each Team}

Students will be able to understand the completed program correctly, create questions on a team-by-team basis, and freely define the results of their own aptitude test. A template form shown in Table 5 can be used for this team activity, according to the problem-solving steps using the software. During the five problem-solving steps, students will use 'divide and conquer' programming technique. Finally, they have to study and explain about how their programs are created by their data structures and computation methods. 
Table 5. A Template Form used for this Team Activity

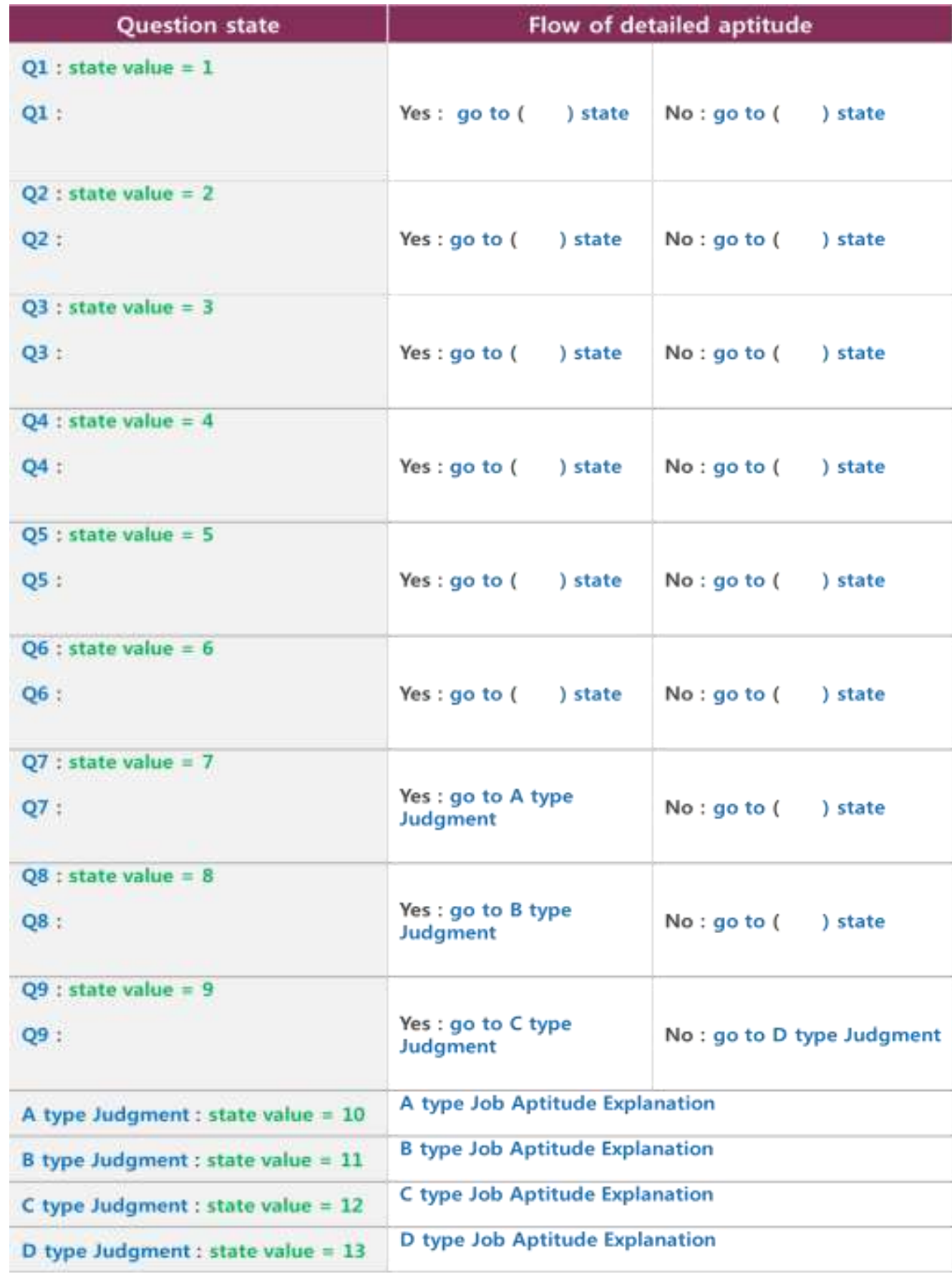

\section{Conclusion}

The proposed IT aptitude test program was systematically developed according to the problem-solving steps using the software. By using the developed IT aptitude testing program, it is possible to clearly train the programming structure that utilizes the variable memory space and to improve the understanding of the 'Divide and conquer' programming technique. We will propose an IT aptitude test program using the List data structure as the next research topic. 


\section{Author Contributions}

Kyeong Hur wrote the manuscript. Won-Sung Sohn designed experiments. Kil Young Kwon provided technical support.

\section{Acknowledgments}

This paper is a revised and expanded version of a paper entitled 'Education Stages for Understanding of 'Problem Solving process' using 'Software' presented at 2017 1st International Conference on Convergent Research Theory and Technology (CRTT 2017), August 20, 2017, Jeju National University, Korea.

\section{References}

[1] Y. J. Lee, J. W. Hwang, D. M. Hwang, K. M. Yun, B. G. Lee, S. T. Yu and I. Y. Moon, "Design and Implementation of Software Program based on Web for Basic Electronic Circuit Practice", Journal of Practical Engineering Education, vol. 7, no. 2, (2015), pp. 113-117.

[2] Y. J. Kim, "Development and Application of STEAM Education Program by Producing UCC", Journal of The Korean Association of information Education, vol. 17, no. 3, (2013), pp. 339-346.

[3] S. F. Najam, M. L. P. Tan and Y. S. Yu, "General SPICE Modeling Procedure for Double-Gate Tunnel Field-Effect Transistors", Journal of Information and Communication Convergence Engineering, vol. 14, no. 2, (2016), pp. 115-121.

[4] National Center for Career Information Network, Ministry of Education, Korea, Available at: http://www.career.go.kr.

[5] National Center for All Jobs in Korea, Ministry of Employment and Labor, Korea, Available at: http://www.work.go.kr.

[6] A. Elzamly, B. Hussin, S. S. A. Naser and M. Doheir, "Classification of Software Risks with Discriminant Analysis Techniques in Software planning Development Process", International Journal of Advanced Science and Technology, vol. 81, (2015), pp. 35-48.

[7] G. Chandrika, "Study on Software Reliability and Reliability Testing", Asia-pacific Journal of Convergent Research Interchange, vol. 1, no. 1, (2015), pp. 7-20.

[8] S. H. Sung and P. Z. Khan, "Quantitative and Qualitative Approach for IT Risk Assessment", Asiapacific Journal of Convergent Research Interchange, vol. 1, no. 1, (2015), pp. 29-35.

[9] S. M. Shin and Sk. Uroosa, "Predicting Software Reliability Using Particle SWARM Optimization Technique", Asia-pacific Journal of Convergent Research Interchange, vol. 1, no. 3, (2015), pp. 17-30.

[10] M. S. Srinivas and G. Pradeepini, "Feature Selection based Neural Networks for Software Defect Prediction", International Journal of Security Technology for Smart Device (IJSTSD), vol. 1, no. 1, (2014), pp. 7-12.

[11] J. Tae, "Development of STEAM Education Program Utilizing IoT Teaching Aid for Middle School Students and Its Application", International Journal of Computer Science and Information Technology for Education (IJCSITE), vol. 2, no. 1, (2017), pp. 15-20.

[12] J.-H. Eom, "Problems and Improvement of the Curriculum for Effective Cyber Security Education and Training”, Journal of Security Engineering, vol. 12, no. 4, (2015), pp. 337-350.

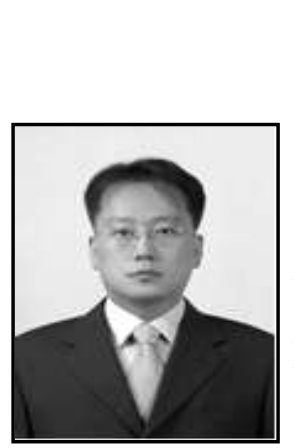

\section{Authors}

Kyeong Hur, he is currently a professor in the Department of Computer Education at Gyeongin National University of Education, Republic of Korea. He was senior researcher with Samsung Advanced Institute of Technology (SAIT), Korea from September 2004 to August 2005. He received a M.S. and Ph.D. in Department of Electronics and Computer Engineering from Korea University, Seoul, Korea, in 2000 and 2004, respectively. His research interests include; computer network designs and computer science education. 


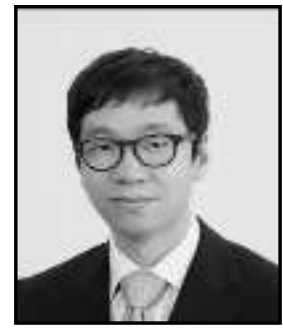

Won-Sung Sohn, he received the B.S. and M.S. degrees in Computer Engineering from Dongkuk University in 1998 and 2000 and the Ph.D. degree in Computer Science from Yonsei University in 2004. From 2004 to 2006. He was a postdoctoral associate in the Computational Design Laboratory at Carnegie Mellon University. He is currently a professor at Department of Computer Education, Gyeongin National University of Education. His research interests include educational design research, human-computer interaction and computer education.

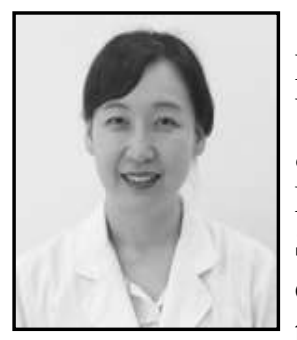

Kil Young Kwon, she is currently an assistant professor in the Department of Family Medicine at Eulji General Hospital and Eulji University, the Republic of Korea. She served as Internship, Resident \& Fellow in the Severance Hospital at Yonsei University College of Medicine, Republic of Korea from March 2001 to February 2006. She received an M.S. International Health Science in the Department of Public Health, Yonsei University and Ph.D. Integrated Medicine in the Department of Medicine, Cha University, Seoul, Korea, in 2008 and 2015 , respectively. 
International Journal of Advanced Science and Technology

Vol.116 (2018) 